\title{
Eskişehir İlinde Yem Bitkileri Ekiliş Alanı ve Üretim Miktarı Üzerine Tarımsal Desteklemelerin Etkisi
}

\author{
Nihal Can AĞIRBAŞ ${ }^{1^{*}} \quad$ Kadriye SAPMAZ ${ }^{2} \quad$ Ali KOÇ \\ ${ }^{1}$ Eskişehir Osmangazi Üniversitesi Ziraat Fakültesi, Eskişehir \\ ${ }^{2}$ Eskişehir Osmangazi Üniversitesi Diş Hekimliği Fakültesi, Eskişehir \\ (*Sorumlu yazar email: ncagirbas@ogu.edu.tr)
}

\begin{abstract}
ÖZET : Yem bitkileri; hayvancılık yapılan işletmelerce üretildiğinde, maliyetleri önemli oranlarda düşürmesinin yanında, yetiștirildikleri toprakların fiziksel ve kimyasal özelliklerine olumlu etkisinden dolayı da büyük öneme sahiptir. Bu nedenle pek çok ülkede olduğu gibi Türkiye'de de, devlet tarım politikalarıyla desteklenen ürünlerdendir. Destekleme yöntem ve tutarlarında yapılan değişikliklerin, çiftçilerden başlayarak bölgesel ve ülkesel etkiler yarattığı bir gerçektir. Bu etkilerin düzeyinin bilinmesi, gelecek dönemlerde yem bitkilerine uygulanacak desteklerin belirlenmesinde önemlidir. Bu amaçla çalışmada, 2000-2016 yılları arasında yem bitkileri desteklerinin, Eskişehir ilinde yem bitkileri ekilişi ve üretim miktarı üzerine etkileri incelenmiştir. 2015 yılında ilde çayır mera kaynaklı üretilen faydalı ot üretiminin yaklaşı 100000 ton, yem bitkileri kaynaklı kuru otun ise 205798 ton olduğu belirlenmiştir. Buna karşllık 2015 yllında, ilde 138077 Hayvan Birimi (HB) hayvan bulunduğu ve bu hayvanların sadece yaşama payı kaba yem gereksinimlerini karşılamak için 724473 ton kuru ot gereksiniminin olduğu hesaplanmıştır. Bu durumda Eskişehir'de ortaya çıkan 418675 ton kaliteli kaba yem açığı, hasat artıkları ile giderilmektedir. Son on yıl içerisinde ilde yem bitkileri ekiliş alanı \% 49 artışla 10500 hektardan 15664 hektara, üretim miktarı \% 78 artışla 115817 tondan 205798 tona yükselmiș, buna karșıllk yem bitkilerine yapılan destek tutarı 2015 yılı reel fiyatlarıyla son on yılda \% 5.28 azalmıștır. Yıllar itibariyle yapılan değerlendirmelerde; destekleme tutarının değişmesi yanında, destekleme politikasının sürekliliğinin, çiftçilerin yem bitkisi yetiştirme isteğine, bu durumun da yem bitkisi ekim alanı ve üretim miktarlarında artışa neden olduğu söylenebilir.
\end{abstract}

Anahtar kelimeler: Tarımsal desteklemeler, yem bitkileri

\section{The Effects of Agricultural Supports on Forage Crops of Cultivation Area and Amount of Production in Eskişehir Province}

\begin{abstract}
Beside significant effect on decreasing the cost of feeding animals, producing their own forage crops will provide positive physical and chemical outcomes to land that they have planted. Because of that positive effects, cultivation of forage crops are supported in Turkish farming regulations among with many countries. It is the fact that, the effects of change in supportive methods and amounts of that supports will start at individual farmer level and regional level it will continue to country level effects. In order to apply new forage crops support methods for farmers it is important to determine and understand the effects of these farmers and country based changes in future. In this study, the impacts of these supports on amount of crops that produce in Eskişehir, between 2000 and 2016 is analyzed and calculated. In these calculations it is stated that in 2015 the amount of rangeland based hay is about $100000 \mathrm{t}$., the amount of hay produced from the field area is $205798 \mathrm{t}$. However, there are 138 077 animal unit (AU) in 2015 in Eskișehir and 724473 t. hay is required for livestock per year to meet their maintenance needs. Derived from these information, there is shortage of high quality hay in the amount of to $418675 \mathrm{t}$. and this gap is filled through field crop residues. Compared to last ten years in Eskișehir forage crop cultivation areas have raised $49 \%$ from 10500 ha to 15 664 ha. Production have raised $79 \%$ from 115817 t. to 205798 t. On the contrary, amount of forage crops supplies have decreased with $5.28 \%$ real prices in 2015. When considering recent year's results, besides the changes in the rate of supports, continuity of supporting the policy is more effective than quantity of these supports on farm level. Therefore; continuity of these policies are causing on promote cultivation area and quantity of forage crops.
\end{abstract}

Keywords: Agricultural supports, forage crops

\section{GİRIŞ}

Yem bitkileri, hayvansal üretimde en önemli girdilerden birini oluşturan kaba yemi sağlamasının yanı sıra, ekim nöbetinde kendisini takip eden bitkilerin verim ve kalitesine olumlu etki yapmalarından dolayı da büyük öneme sahiptir. Sürdürülebilir tarım açısından ekim nöbeti her ne kadar yaşamsal öneme sahip (Açıkgöz vd., 2005) olsa da ürün-fiyat politikalarındaki dengesizlikler etkin ekim nöbeti uygulamalarına firsat vermemekte ve bazı ürünlerin sistemde daha yoğun yer almasına neden olmaktadır. $\mathrm{Bu}$ olumsuzluğu ortadan kaldırmak için fiyat veya destek politikalarına sık sık başvurulmaktadır. Nitekim ülkemizde tarla tarımı sistemlerinde yem bitkilerinin payını artırmaya yönelik destek politikaları yürürlüğe konulmuş olmakla birlikte ortaya konulan mevcut politikanın yem bitkileri yönünden etkinliği yörelere göre değişmektedir. Zira ülkemizin ekolojik yapısı yörelere göre ürün verimliliğinde önemli farklılıklara sebep olmaktadır.

Son yıllarda gerek nüfus artışı, gerek ise satın alma gücündeki artışa paralel olarak hayvansal ürünlere talep artmış ve bu artışa bağlı olarak kültür ırkı veya bunların melezlerinden meydana gelen sığır sürüleri ile oluşturulan entansif ve yarı entansif işletmelerde artış olmuştur. $\mathrm{Bu}$ işletmelerde ahırda 
besleme ağırlıklı bir yer tuttuğundan kaba yemlere ihtiyaç artmaktadır (Yolcu ve Tan, 2008). Ruminant beslemede giderlerin \%70'ini yem giderleri oluşturmaktadır (Alçiçek, 2002). Yemin kalitesi ile hayvan performansı arasında yakın bir ilişki olduğu bilinen bir gerçektir (Koc vd., 2014). Neticede hayvancılık işletmelerinde verimlilik ve buna bağlı olarak karlılığın artırılması her şeyden önce kaliteli kaba yem temini ile mümkündür. Dolayısıyla ülkemizde hayvancılıkta verimliliği artırmak için hayvan beslemede kaba yem kaynağı olarak bitkisel artıklar (sap, saman vb) yerine yem bitkilerinin kullanımına öncelik verilmesi zorunludur. Bu konuda başarılı olabilmek için de ülkemiz tarım politikalarında yem bitkileri desteklemelerinin öncelikli yer alması gerekmektedir. Zira yem bitkilerinde birim alandaki getiri, mevcut ürün-fiyat uygulamalarında yem bitkilerinin aleyhine bir durum sergilemektedir. Nitekim çiftçilerin yem bitkisi ekimi tercihleri ile ilgili olarak Ankara ili Polatlı ilçesinde yapılan bir çalışmada (Yavuz ve Ceylan, 2004) çiftçilerin yem bitkisi ekimi tercihlerinde bireysel tercih ve işletme özelliklerinin yanı sıra en önemli faktörün yem bitkilerinin getirisi olduğuna vurgu yapılmıştır.

Ülkemizde yem bitkilerinin mevcut durumu ve ihtiyaç konusunda çok sayıda çalışma mevcut olsa da (Açıkgöz vd., 2005; Yolcu ve Tan, 2008; Sabancı vd., 2010; Avcıŏlu vd., 2000; Alçiçek vd., 2010; Çelik ve Demirbağ, 2013; Özkan ve Demirbağ, 2016), bu çalışmalar genelde ülke ölçeğinde yapılmış olup farklı ekolojik özelliklerde yer alan illere veya yörelere göre sınırlı sayıda çalışma mevcuttur (Temel ve Şahin, 2011; Turan vd., 2015; Yavuz ve Ceylan, 2004; Cevher ve Karakurt, 2010; Cevher 2012; Demir ve Yavuz, 2010; Aksu ve Dellal, 2016; Sancar vd., 2014) ve Eskişehir ili genelinde bu yönde yapılmış bir çalışma mevcut değildir.

$\mathrm{Bu}$ çalışma, sulu tarımın yoğun olarak yapıldığı ve profesyonel hayvancılık işletmelerinin sayısının hızla arttığı Eskişehir'de yem bitkilerinin ekiliş alanı ve üretim miktarlarının yıllar itibariyle değişimi ile yem bitkilerine yönelik yapılan desteklemelerin katkısını ortaya koyarak çözüm önerileri sunmak amacıyla planlanmıştır.

\section{MATERYAL ve YÖNTEM}

Tipik bozkır (step) ikliminin hakim olduğu İç Anadolu Bölgesinde yer alan Eskişehir İli 13925 $\mathrm{km}^{2}$ alanıyla Türkiye topraklarının \%1.8'ini kaplamaktadır. İl arazi varlığının \% 41.2'si tarım, \% 24.2'si orman ve \% 23.8'i çayır mera arazisidir (GTHB, 2016a). Deniz seviyesinden yaklaşık $800 \mathrm{~m}$ yükseklikte yer alan Eskişehir Ovası ve civarı arazilerde sulu tarım arazileri il tarım alanlarının \% 23.40'ını meydana getirmektedir. Uzun yıllar ortalamasına göre $352.9 \mathrm{~mm}$ yıllık toplam yağış ve $10.9{ }^{\circ} \mathrm{C}$ yıllık ortalama sıcaklığa sahip olan ilde tarımsal üretimde verimlilik açısından sulama hayati öneme sahiptir. İl tarım arazilerinin \% 65.33'ü yem bitkilerinin de içinde yer aldığı tarla alanı olarak değerlendirilirken $\% \quad 32.20$ oranında nadas uygulaması yapılmaktadır (GTHB, 2016b).

Çalışmada Türkiye İstatistik Kurumu (TÜİK) verileri, T.C. Gıda Tarım ve Hayvancılık Bakanlığı (GTHB) Faaliyet Raporları, Eskişehir İl Gıda Tarım ve Hayvancılık Müdürlüğü Çiftçi Kayıt Sistemi (ÇKS) Kayıtları kullanılmıştır. Ele alınan veriler 2000-2015 yılları arasındaki zaman serileri şeklinde değerlendirilmiştir. Reel fiyat hesaplamalarında Yurt İçi Üretici Fiyat Endeksi (YÜFE) kullanılmıştır. Mevcut hayvan varlığ 1 ve ihtiyaç duyulan kaba yem miktarı Hayvan Birimi (HB) cinsinden hesaplanmıştır. Ele alınan zaman serisi içerisindeki kaba yem üretimindeki değişim yem bitkileri destekleri ile ilişkilendirilmeye çalışılmıştır. Yem bitkileri ekim desteklemesi 2001 yılında başladığ için 2000 yılı destek öncesi olarak kabul edilmiştir.

\section{BULGULAR \\ Eskișehir İli Yem Bitkileri Ekim Alanındaki Değişim}

Eskişehir ilinde yaklaşık 550 bin hektar civarında ekili tarım arazisi bulunmakta olup ekiliş alanı yıllara göre 445.0 ile 571.4 bin hektar arasında değişmektedir (Çizelge 1). Tarım arazilerinin 2005 yılından sonra ekim alanlarındaki azalış trendi 2012 yılına kadar devam etmiş ve izleyen yıllarda artış göstermiştir.

İlde destekleme öncesi (2000 yılı) 7890 hektar olan yem bitkisi ekim alanı 2001-2004 yılları arasında yapılan desteklerden etkilenmemiş ve bu dönem içerisinde yem bitkileri ekiliş alanında kayda değer bir artış olmamıştır (Çizelge 2). Yem bitkileri ekim alanı 2005 yılından sonra artmaya başlamış ve 2008 yılında 17256 hektar ile en üst seviyeye çıkmıştır. İzleyen süreçte 2011 yılına kadar azalma göstermiş daha sonra tekrar artış eğilimine geçmiştir. İlde 2013 yılında 15 bin hektarın üzerine çıkan yem bitkileri ekim alanı, takip eden 2 yılda (2014-2015) da fazla değişim sergilememiştir.

Destek öncesi ilde ekili alanların \%1.42'sini kaplayan yem bitkileri, desteklemenin başladığı 2003 yılından 2015'e kadar \%1.03 ile \% 3.26 arasında değişim göstermiştir. Son yıllarda bu oran \% 2.76 seviyelerinde kalmıştır. Ekiliş alanı destek öncesine göre 2005-2009 y1lları arasında pozitif, 2010-2011 yıllarında negatif bir eğilim ve bu yıldan sonra tekrar artışa geçerek son yıllarda 198 seviyelerine ulaşmıştır. Yem bitkileri ekiliş alanı 2015 yılı itibarı ile destek öncesine göre \% 98 artış göstermiştir. 
Çizelge 1. Eskişehir İli Yem Bitkileri Ekiliş Alanları ve Üretim Miktarları

\begin{tabular}{|c|c|r|r|r|r|}
\hline Yillar & $\begin{array}{c}\text { Toplam Alan } \\
\text { (ha)* }\end{array}$ & $\begin{array}{c}\text { Yem Bitkileri } \\
\text { Ekiliş Alanı (ha)* }\end{array}$ & $\begin{array}{c}\text { Ekiliş } \\
\text { Alanı İndeksi** }\end{array}$ & $\begin{array}{c}\text { Toplam Ekiliş } \\
\text { Alanı İçindeki Payı } \\
(\mathbf{\%})\end{array}$ & $\begin{array}{c}\text { Kuru Ot Üretim } \\
\text { Miktarı (ton)**** }\end{array}$ \\
\hline $\mathbf{2 0 0 0}$ & 556937 & 7890 & 100.00 & 1.42 & 69746 \\
\hline $\mathbf{2 0 0 1}$ & 550174 & 7399 & 93.66 & 1.34 & 60954 \\
\hline $\mathbf{2 0 0 2}$ & 544631 & 7044 & 89.28 & 1.29 & 78220 \\
\hline $\mathbf{2 0 0 3}$ & 529536 & 5431 & 68.83 & 1.03 & 62829 \\
\hline $\mathbf{2 0 0 4}$ & 552377 & 7647 & 96.92 & 1.41 & 92217 \\
\hline $\mathbf{2 0 0 5}$ & 551226 & 10500 & 133.08 & 1.90 & 115817 \\
\hline $\mathbf{2 0 0 6}$ & 545892 & 12968 & 164.36 & 2.38 & 129526 \\
\hline $\mathbf{2 0 0 7}$ & 534053 & 16946 & 214.78 & 3.17 & 138149 \\
\hline $\mathbf{2 0 0 8}$ & 529910 & 17256 & 218.71 & 3.26 & 157427 \\
\hline $\mathbf{2 0 0 9}$ & 500682 & 12061 & 152.86 & 2.41 & 108608 \\
\hline $\mathbf{2 0 1 0}$ & 445041 & 10365 & 131.37 & 2.33 & 82194 \\
\hline $\mathbf{2 0 1 1}$ & 476559 & 9490 & 120.28 & 1.99 & 81047 \\
\hline $\mathbf{2 0 1 2}$ & 460456 & 12730 & 161.34 & 2.76 & 94052 \\
\hline $\mathbf{2 0 1 3}$ & 563062 & 15353 & 194.59 & 2.73 & 214860 \\
\hline $\mathbf{2 0 1 4}$ & 571398 & 15760 & 199.75 & 2.76 & 200693 \\
\hline $\mathbf{2 0 1 5}$ & 567545 & 15664 & 198.53 & 2.76 & 205798 \\
\hline
\end{tabular}

* işaretli veriler TÜİK 2016a'dan alınmıştır,

** Ekiliş alan indeksi hesaplamasında destek öncesi 100 alınmıştır.

*** Yaş ot veriminde mısır ağırlıklı olduğu için kuru madde oranı \%35 alınmış ve kuru otun \%85 kuru madde içerdiği varsayılarak hesaplanmıştır.

Yem bitkileri desteklemesinin yürürlüğe girdiği dönemde ekimi yapılan yem bitkisi cinsinde de önemli değişimler meydana gelmiştir (Çizelge 2). Destek öncesi 7368 hektar olan yonca ekim alanı, destekleme döneminde 4264 ile 6933 hektar arasinda, 2015 yilında $6 \quad 814$ hektar olarak kaydedilmiştir. Destekleme döneminde yonca ekim alanlarında destek öncesine göre bir artış ortaya çıkmamışıtır. Ancak sonraki yıllarda yonca ekimine olumlu katk1 sağlamış ve 2011 yılına göre 2015 yılında yonca ekim alanlarında yaklaşı \% 59'luk bir artış kaydedilmiştir. İlde fiğ ekiliş 2004 yılında kayıtlara girmiş ve 2008 yılına kadar sürekli artarak 7 448 hektara ulaşmıştır. Silajlık mısır yetiştiriciliğinde ise düzenli artış dikkat çekmiş ve 2015 yılında 4170 hektara ulaşmıştır. Korunga ekim alanlarında ise destek öncesine göre belirgin bir düşüş olmuştur. Son y1llarda yem bitkisi olarak ilde sorgum ve tritikale ekiminin yapıldığı, burçak ekiminden vazgeçildiği ve 2006-2007 yıllarında 100 hektarı aşmış olmakla birlikte kısitlı bir alanda da olsa hayvan pancarı yetiştirildiği görülmektedir (Çizelge 2).

\section{Eskişehir İli Hayvan Varlığı ve Kaba Yem İhtiyacı}

Eskişehir ili hayvan varlı̆g ve kaba yem ihtiyacına ait veriler Çizelge 3'de sunulmuştur. İl toplam hayvan varlığı 138077 HB'ne eşit olup bu varlı̆ğın yarıdan fazlasını büyükbaş hayvan ( 75846 HB ) oluşturmaktadır.
Mera kanunun ilgili mevzuatında 1 HB'nin günlük $12.5 \mathrm{~kg}$ kuru ot tüketeceği ve otun \%15'inin nakliye vb. yolla kaybolacağı varsayılarak yapılan hesaplamada (138 077 x $12.5 \times 365 \times 1.15)$ il hayvan varlığı için 724473 ton kuru ota ihtiyaç vardır. İlde 325851 hektar mera alanı olup bu alanların faydalı ot üretimi dekara $30 \mathrm{~kg}$ civarındadır (Altın vd., 2011). Buna göre il meralarından yaklaşı 100 bin ton civarında kuru ot üretilmektedir. Yem bitkileri tarımından 2015 y1lı için elde edilen toplam kuru ot miktarı 205798 ton olup geri kalan 418675 ton açık, hasat artıkları ile karşılanmaktadır.

İlin mevcut çayır mera alanı düşünüldüğünde bu açığın çayır mera yoluyla kapatılması olası değildir. Ülke geneli için de aynı durum söz konusudur. Bu durumda uygulanması gereken yöntem, yem bitkileri üretimini arttırmaktır. Bu nedenle özellikle son yıllarda Türkiye'de yem bitkileri ekilişini artırmak için farklı destekleme yöntemleri kullanılmaktadır.

\section{Yem Bitkilerine Uygulanan Desteklemelerin Zaman İçerisindeki Değişim Seyri}

Yem bitkileri desteklemelerinin başladığı 2001 yılından itibaren destekleme yöntemlerinde duyulan ihtiyaca göre düzenlemeler yapılmış ve bu değişimlerin sağlıklı algılanabilmesi için verilen destekler 2015 yılı reel değerlerine çevrilerek Çizelge 4 ve 5 'te özetlenmiştir. 
Çizelge 2. Eskişehir İlinde Tarımı Yapılan Yem Bitkileri ve Ekiliş Alanları (ha.) (TÜIK, 2016a).

\begin{tabular}{|c|c|c|c|c|c|c|c|c|c|}
\hline Yıllar & Yonca & Fiğ & $\begin{array}{c}\text { Silajlık } \\
\text { Mısır }\end{array}$ & Korunga & Sorgum & $\begin{array}{c}\text { Hayvan } \\
\text { Pancarı }\end{array}$ & Tritikale & Burçak & $\begin{array}{c}\text { Genel } \\
\text { Toplam }\end{array}$ \\
\hline $\mathbf{2 0 0 0}$ & 7368 & & & 492 & & 30 & & & 7890 \\
\hline $\mathbf{2 0 0 1}$ & 6931 & & & 410 & & 58 & & & 7399 \\
\hline $\mathbf{2 0 0 2}$ & 6564 & & & 400 & & 80 & & & 7044 \\
\hline $\mathbf{2 0 0 3}$ & 5140 & & & 226 & & 65 & & & 5431 \\
\hline $\mathbf{2 0 0 4}$ & 4836 & 1011 & 1608 & 106 & & 34 & & 52 & 7647 \\
\hline $\mathbf{2 0 0 5}$ & 6165 & 1956 & 2164 & 124 & & 61 & & 30 & 10500 \\
\hline $\mathbf{2 0 0 6}$ & 6582 & 3667 & 2457 & 153 & & 100 & & 9 & 12968 \\
\hline $\mathbf{2 0 0 7}$ & 6502 & 7379 & 2765 & 189 & & 111 & & & 16946 \\
\hline $\mathbf{2 0 0 8}$ & 6416 & 7448 & 3120 & 175 & & 97 & & & 17256 \\
\hline $\mathbf{2 0 0 9}$ & 4961 & 4145 & 2768 & 112 & & 75 & & & 12061 \\
\hline $\mathbf{2 0 1 0}$ & 4590 & 3108 & 2495 & 122 & & 50 & & & 10365 \\
\hline $\mathbf{2 0 1 1}$ & 4264 & 2533 & 2561 & 93 & & 39 & & & 9490 \\
\hline $\mathbf{2 0 1 2}$ & 5968 & 3751 & 2896 & 74 & & 35 & 6 & & 12730 \\
\hline $\mathbf{2 0 1 3}$ & 5899 & 5462 & 3802 & 69 & 50 & 40 & 31 & & 15353 \\
\hline $\mathbf{2 0 1 4}$ & 6680 & 4701 & 4171 & 122 & 53 & 33 & & & 15760 \\
\hline $\mathbf{2 0 1 5}$ & 6814 & 4465 & 4170 & 123 & 40 & 33 & 19 & & 15664 \\
\hline
\end{tabular}

Çizelge 3. Eskişehir İli 2015 Yılı Tür, Yaş ve Irklara Göre Hayvan Varlı̆̆ı (Baş) (HB)

\begin{tabular}{|c|c|c|c|c|c|c|c|}
\hline Hayvan Türü & \multicolumn{4}{|c|}{ Irk } & \multirow{3}{*}{ Toplam } & \multirow{3}{*}{$\begin{array}{c}\text { HB } \\
\text { Katsayıları } \\
(* *)\end{array}$} & \multirow{3}{*}{$\begin{array}{c}\text { Toplam } \\
\text { HB }\end{array}$} \\
\hline \multicolumn{5}{|c|}{ Büyükbaş Hayvan Sayısı (*) } & & & \\
\hline & Kültür & K.Melezi & Yerli & Manda & & & \\
\hline Sığır & 35305 & 16966 & 6433 & & 58704 & $1.00 ; 0.75 ; 0.50$ & 51246 \\
\hline Dana-Düve & 18243 & 8457 & 9627 & & 36327 & $0.60 ; 0.45 ; 0.30$ & 17640 \\
\hline Buzağı (Dişi-Er.) & 17838 & 8638 & 3351 & & 29827 & 0.06 & 1790 \\
\hline Manda (Erkek) & & & & 99 & 99 & 0.90 & 89 \\
\hline Manda (Dişi) & & & & 226 & 226 & 0.75 & 170 \\
\hline Boğa & 1429 & 827 & 1013 & & 3269 & 1.50 & 4903 \\
\hline Öküz & - & - & 14 & & 14 & 0.60 & 8 \\
\hline \multirow[t]{3}{*}{ Toplam } & 72815 & 34888 & 20438 & 325 & 128466 & & 75846 \\
\hline & \multicolumn{5}{|c|}{ Küçükbaş Hayvan Sayısı (*) } & & \\
\hline & Merinos & Yerli & Kil & Tiftik & Toplam & & \\
\hline Koyun & 291651 & 101253 & & & 392904 & 0.10 & 39290 \\
\hline Keçi & & & 40283 & 5798 & 46081 & 0.08 & 3687 \\
\hline Kuzu & 210656 & 89852 & & & 300508 & 0.04 & 12020 \\
\hline Oğlak & & & 61383 & 7516 & 68899 & 0.04 & 2756 \\
\hline \multirow[t]{2}{*}{ Toplam } & 502307 & 191105 & 101666 & 13314 & 808892 & & 57753 \\
\hline & \multicolumn{5}{|c|}{ Tek Turnaklı Hayvanlar (*) } & & \\
\hline At & & & & & 2370 & 0.50 & 1185 \\
\hline Katır & & & & & 126 & 0.40 & 50 \\
\hline Eşek & & & & & 3346 & 0.30 & 1004 \\
\hline & & & & & Toplam & & 2239 \\
\hline & & & & & oplam HB & & 138077 \\
\hline
\end{tabular}

Kaynak: TÜİK, 2016 b.

** TKB, 2001., ( 4342 Sayılı Yeni Mera Kanunu yönetmeliği Madde 6/a' da belirtilmiş katsayılardır).

Eskişehir ilinde desteklenen alan ve desteklenen çiftçi sayısı değişimleri incelendiğinde, yem bitkileri ekiliş alanı \% 98 artışla 7890 hektardan 15664 hektara yükselirken, aynı süreçte desteklenen alanda da \% 253'lük bir artış olmuştur. Yıllar itibariyle ekiliş̧ alanının artmasına bağlı olarak yem bitkileri üretim miktarında önemli artışlar meydana gelmiştir. Yem bitkileri üretimi 2000 yllında 69746 ton iken 2015 
yılında \% 195'lik artışla 205798 tona yükselmiştir. Son on yıl içerisinde desteklenen çiftçi sayısı ise 2303 kişiden 1858 kişiye düşmüştür (Çizelge 4).

Destekleme tutarları 2015 yılı reel fiyatlarıyla irdelendiğinde, yem bitkileri ekiliş alanı ve üretim miktarlarındaki önemli artışa karşlık son on yılda yem bitkilerine yapılan toplam destek tutarının reel fiyatlarla \%5.28 azaldığı görülmektedir. (Çizelge 5) Yem bitkileri ekiliş alanına düşen destekleme tutarı açısından bakıldığında 2005 yılında, 2015 yılı reel fiyatlarıyla $345.88 \mathrm{TL} / \mathrm{ha}$ olan destekleme tutarının, 2015 yılında \%36.50'lik azalışla 219.62 TL/ha.'a düştüğü görülmektedir. Desteklenen alan \% 253 artarken, desteklenen alana düşen destekleme tutarı \% 35.83 oranında azalmıştır. Destekleme tutarındaki değişimlerin çiftçi üzerindeki etkisinin görülebilmesi açısından çiftçi başına ödenen destekleme tutarları Çizelge 5'te sunulmuştur. Yıllara göre incelendiğinde; 2005 yılında çiftçi başına düşen destekleme tutarı 2015 yılı reel fiyatlarıyla 1576.98 TL iken, 2015 y1lında \% 17.40 artarak 1851.49 TL'ye yükselmiştir. Ancak bu durumun, aynı yıllar içerisinde desteklenen çiftçi sayısındaki \% 19.32'lik azalıştan kaynaklandığı söylenebilir. Son on yıl içerisinde yem bitkileri desteğinden yararlanan çiftçi sayısı azalmıştır. Yem bitkisi desteklemelerinin büyük arazi sahibi çiftçiler lehine işlediği sonucuna ulaşılmaktadır. $\mathrm{Bu}$ durum, uygulamada küçük çiftçilerin destekleme isteği ve başvurusunun azalması şeklinde ortaya çıkmaktadır.

Çizelge 4. Eskişehir İli Yem Bitkileri Desteklenen Alan, Çiftçi Sayısı ve Tutarları

\begin{tabular}{|c|c|c|r|r|r|}
\hline Yıllar & $\begin{array}{c}\text { Yem Bitkileri } \\
\text { Ekiliş Alanı } \\
\text { (ha) }\end{array}$ & $\begin{array}{c}\text { Üretim } \\
\text { Miktarı } \\
\text { (ton) }\end{array}$ & $\begin{array}{c}\text { Yem Bitkileri } \\
\text { Desteklenen } \\
\text { Alan Toplamı (ha) }\end{array}$ & $\begin{array}{c}\text { Desteklenen } \\
\text { Ciftçi Sayısı } \\
\text { (Adet) }\end{array}$ & $\begin{array}{c}\text { Destekleme Tutarı } \\
\text { (Cari Fiyatlarla) } \\
\text { (TL) }\end{array}$ \\
\hline $\mathbf{2 0 0 0}$ & 7890 & 69746 & 251.84 & 49 & 35125.64 \\
\hline $\mathbf{2 0 0 1}$ & 7399 & 60954 & 963.67 & 379 & 118252.11 \\
\hline $\mathbf{2 0 0 2}$ & 7044 & 78220 & 1248.67 & 371 & 262593.21 \\
\hline $\mathbf{2 0 0 3}$ & 5431 & 62829 & 2064.51 & 614 & 534458.34 \\
\hline $\mathbf{2 0 0 4}$ & 7647 & 92217 & 3044.14 & 1387 & 1011889.00 \\
\hline $\mathbf{2 0 0 5}$ & 10500 & 115817 & 4320.75 & 2303 & 1746547.09 \\
\hline $\mathbf{2 0 0 6}$ & 12968 & 129526 & 7045.88 & 3514 & 4616030.43 \\
\hline $\mathbf{2 0 0 7}$ & 16946 & 138149 & 8649.56 & 3090 & 5360969.16 \\
\hline $\mathbf{2 0 0 8}$ & 17256 & 157427 & 7742.93 & 2320 & 3128890.75 \\
\hline $\mathbf{2 0 0 9}$ & 12061 & 108608 & 5040.53 & 1571 & 2151441.41 \\
\hline $\mathbf{2 0 1 0}$ & 10365 & 82194 & 4708.19 & 1509 & 2163673.81 \\
\hline $\mathbf{2 0 1 1}$ & 9490 & 81047 & 5354.91 & 1644 & 2776840.66 \\
\hline $\mathbf{2 0 1 2}$ & 12730 & 94052 & 7015.75 & 2067 & 3719382.74 \\
\hline $\mathbf{2 0 1 3}$ & 15353 & 214860 & 8301.36 & 2425 & 5255238.02 \\
\hline $\mathbf{2 0 1 4}$ & 15760 & 200693 & 7292.99 & 2147 & 4308681.73 \\
\hline $\mathbf{2 0 1 5}$ & 15664 & 205798 & 6376.07 & 1858 & 3440067.04 \\
\hline
\end{tabular}

Kaynak: GTHB, 2016c.

Alan bazlı destekleme grubunda olmaları dolayısıyla yem bitkisi desteklemelerinin birim alana (hektara) düşen payının son on yılda yaklaşık \% 36 oranında azalmış olması da yem bitkileri destek etkinliğinin hem sosyal, hem de ekonomik açıdan giderek düşmekte olduğu şeklinde yorumlanabilir.

\section{TARTISMA}

İncelenen dönem içerisinde il genelinde yem bitkisi ekiliş alanlarında dalgalanmalar dikkat çekmektedir. Ekim alanlarının artış ve azalışlarında ortaya çıkan bu değişimlerde ürün-fiyat politikalarının etkisinin olma olasılığı yüksektir. Zira birim alandan elde edilen net gelirin azalmasının üreticiyi üretimden kaçışa yönlendirmesi beklenen bir durumdur (Dinler 2000; Rehber, 2013). Son yıllardaki eğilim incelendiğinde, özellikle 2012 yılından sonra uygulanan ürün-fiyat politikalarının çiftçiyi tatmin edici boyutta olduğunu söylemek mümkündür. Yem bitkileri desteklerinin ekim alanına etkisi incelendiğinde, destekleme süreci içerisinde ekiliş alanlarında dalgalı bir seyir göze çarpmaktadır. Özellikle 2007-2008 yıllarında ekiliş alanlarında belirgin artış izlenmektedir (Çizelge 1). Takip eden süreçte yeniden azalmış ve son yıllarda tekrar artış eğilimine girerek destek öncesi dönemin yaklaşık iki katına çıkmıştır. 
Çizelge 5. 2015 Yılı Reel Fiyatlarıyla Eskişehir İli Yem Bitkileri Destekleme Tutarları (TL)

\begin{tabular}{|c|c|c|c|c|c|c|c|c|}
\hline Yillar & $\begin{array}{c}\text { Toplam } \\
\text { Destekleme } \\
\text { Tutarı } \\
\text { (TL) }\end{array}$ & $\begin{array}{l}2015 \text { yılı Reel } \\
\text { Fiyatlariyla } \\
\text { Toplam } \\
\text { Destekleme } \\
\text { Tutarı } \\
\text { (TL) }\end{array}$ & $\begin{array}{c}\text { Ekiliş } \\
\text { Alanına } \\
\text { Düşen } \\
\text { Destekleme } \\
\text { Tutarı } \\
\text { (TL/ha) }\end{array}$ & $\begin{array}{c}2015 \text { yılı Reel } \\
\text { Fiyatlarıyla } \\
\text { Ekiliş Alanına } \\
\text { Düssen } \\
\text { Destekleme } \\
\text { Tutarı } \\
\text { (TL/ha) }\end{array}$ & $\begin{array}{c}\text { Desteklenen } \\
\text { Alana Düşen } \\
\text { Destekleme } \\
\text { Tutarı } \\
\text { (TL/ha) }\end{array}$ & $\begin{array}{c}2015 \text { yilı Reel } \\
\text { Fiyatlaryla } \\
\text { Desteklenen } \\
\text { Alana Düssen } \\
\text { Destekleme } \\
\text { Tutarı } \\
\text { (TL/ha) }\end{array}$ & \begin{tabular}{|c} 
Çiftçi \\
Başına \\
Düssen \\
Destekleme \\
Tutarı \\
(TL/kişi)
\end{tabular} & \begin{tabular}{|c|}
2015 yılı Reel \\
Fiyatlarıla \\
Çiftçi Başına \\
Düssen \\
Destekleme \\
Tutarı \\
(TL/kiși) \\
\end{tabular} \\
\hline 2000 & 35125.64 & 270125.40 & 4.45 & 34.24 & 139.48 & 1072.61 & 716.85 & 5512.76 \\
\hline 2001 & 118252.11 & 562177.72 & 15.98 & 75.98 & 122.71 & 583.37 & 312.01 & 1483.31 \\
\hline 2002 & 262593.21 & 850292.06 & 37.28 & 120.71 & 210.30 & 680.96 & 707.80 & 2291.90 \\
\hline 2003 & 534458.34 & 1335233.44 & 98.41 & 245.85 & 258.88 & 646.76 & 870.45 & 2174.64 \\
\hline 2004 & 1011889.00 & 2287277.35 & 132.32 & 299.11 & 332.41 & 751.37 & 729.55 & 1649.08 \\
\hline 2005 & 1746547.09 & 3631778.54 & 166.34 & 345.88 & 404.22 & 840.54 & 758.38 & 1576.98 \\
\hline 2006 & 4616030.43 & 8488882.69 & 355.96 & 654.60 & 655.14 & 1204.80 & 1313.61 & 241573 \\
\hline 2007 & 5360969.16 & 9581880.22 & 316.36 & 565.44 & 619.80 & 1107.79 & 1734.94 & 3100.93 \\
\hline 2008 & 3128890.75 & 4778425.05 & 181.32 & 276.91 & 404.10 & 617.13 & 1348.66 & 2059.67 \\
\hline 2009 & 2151441.41 & 3348152.10 & 178.38 & 277.60 & 426.83 & 664.25 & 1369.47 & 2131.22 \\
\hline 2010 & 2163673.81 & 3128072.82 & 208.75 & 301.79 & 459.56 & 664.39 & 1433.85 & 2072.95 \\
\hline 2011 & 2776840.66 & 3643193.86 & 292.61 & 383.90 & 518.56 & 680.35 & 1689.08 & 2216.06 \\
\hline 2012 & 3719382.74 & 4584591.18 & 292.17 & 360.14 & 530.15 & 653.47 & 1799.41 & 2217.99 \\
\hline 2013 & 5255238.02 & 6155648.17 & 342.29 & 400.94 & 633.06 & 741.52 & 2447.71 & 2867.09 \\
\hline 2014 & 4308681.73 & 4598712.26 & 273.39 & 291.80 & 590.80 & 630.57 & 2006.84 & 2141.93 \\
\hline 2015 & 3440067.04 & 3440067.04 & 219.62 & 219.62 & 539.53 & 539.53 & 1851.49 & 1851.49 \\
\hline \multicolumn{2}{|c|}{$\begin{array}{c}\text { 2005-2015 Değişim } \\
\text { Oranlar1 (\%) }\end{array}$} & $\% 5.28$ & & $\% 36.50$ & & $\% 35.83$ & & $\% 17.41$ \\
\hline
\end{tabular}

*Kaynak: Çizelge 4' ten yararlanılarak hesaplanmıştır..

$\mathrm{Bu}$ dönemdeki reel destek değerleri incelendiğinde (Çizelge 5) 2006 ve 2007 yıllarında reel desteklerin en yüksek seviyeye çıktığ1 görülmektedir. Dolayısıyla 2007 ve 2008 yıllarındaki hızlı artışta reel desteklerin etkisi olasıdır. Son dönemdeki artışta ise ürün fiyat politikalarındaki değişimlere bağlı olarak verilen destekler ile birlikte ekimi yapılan yem bitkilerinin ekonomik açıdan rekabet edebilir hale gelmesinden kaynaklandiğ 1 söylenebilir.

Ekimi yapilan yem bitkilerinin ekim alanlarındaki değişim incelendiğinde, desteklemeler ile birlikte tek yıllık yem bitkilerinde, özellikle silajlık mısırda belirgin bir artış olduğu gözlenmektedir. Eskişehir Ovasında şeker pancarı üretiminin yaygın ve getirisinin yüksek olması nedeniyle, tek yıllık yem bitkileri çiftçilerin ürün desenine daha çok uyum sağlamaktadır. Bu durum, çiftçilerin çok yıllık yem bitkilerini tercih etmemesinin temel sebebidir. Zira destekleme öncesi 7368 hektar olan yonca ekim alanı, destekleme süresince değişik destekleme politikalarına rağmen bu değerin üstüne çıkamamış, hatta azalma sergilemiştir. Ancak 2010'lu yıllarda yoncada desteklerin yıllık hale gelmesiyle kısmı bir artış gözlenmiştir. $\mathrm{Bu}$ artışın Eskişehir Ovasından çok çevre ilçelerdeki tarım alanlarında ortaya çıkmış olma olasılığı yüksektir. Desteklemelerin yem bitkileri çeşitliliğine etkisi tek yıllık baklagiller ve silajlık mısır üzerinde olumlu yönde olurken, diğer yem bitkileri üzerinde belirgin bir etki göstermemiştir.

İlde önemli miktarda bir kaba yem açığı söz konusu olup, mevcut destek politikaları bunu kapatabilecek durumda değildir. Ortaya çıkan 418 675 ton kaba yem açığının tamamının yem bitkileri ile kapatılması da akılcı bir yol değildir. İlde samana ek olarak pancar posası, pancar yaprağı gibi değişik tarımsal üretim yan ürünleri hayvan beslemede kullanılmaktadır. Bu durum ülkemize özgü bir durum olmayıp saman ve diğer ürün artıkları dünyanın bir çok ülkesinde bu amaçla kullanılmaktadır (Shaver and Hoffman, 2010; Lardy, 2016). Bu durum göz önüne alınarak uygun rasyon hazırlama formülleri geliştirilmeli ve buna göre ne kadar kaba yeme ihtiyaç duyulduğu net olarak ortaya konulmalıdır. Eskişehir Ovası gibi taban arazilerde tek yıllık yem bitkileri, diğer alanlarda ise başta yonca olmak üzere yem bitkileri destekleme politikalarının yeniden gözden geçirilerek iyileştirilmesinde yarar görülmektedir.

Destekler öncesinde Türkiye'de yem bitkileri ekim alanı toplam ekim alanının \% 3'ünden daha az bir alanı kaplarken (TÜİK 2001), günümüzde \%10'lar düzeyine ulaşmıştır (TÜİK 2016a). Ancak Eskişehir ilinde bu oranda bir artış olmamıştır. Bu durum, yapılan desteklerle dahi yem bitkilerinin, Eskişehir Ovasında diğer ürünler ile ekonomik açıdan yeterli rekabet gücüne ulaşamadığının bir göstergesidir. 


\section{ÖNERILER}

Eskişehir ilinde yem bitkileri ekim alanı yıllar itibariyle yaklaşık iki katına çıkarken, üretilen kaba yem miktarı üç kat artış göstermiştir. Buna rağmen ildeki yem bitkilerinin ekiliş alanlarındaki payı ülke ortalamasının oldukça altındadır. İlde yem bitkileri tarımını artırmak için taban arazilerde tek yıllık yem bitkilerinin, diğer arazilerde ise başta yonca ve tek yıllık yem bitkilerinin tarımının desteklenmesi etkili olacaktır. Destek miktarları belirlenirken salt ürün cinsi dikkate alınarak değil, diğer ürünlerin fiyatları da gözetilerek yem bitkilerinin ekonomik açıdan rekabet edebilirliği sağlanmalıdır. Nitekim reel destek fiyatları incelendiğinde, son yıllarda desteklerin azalmasına rağmen ekim alanlarındaki artışın birim alanda yüksek verim sağlayan silajlık mısır yetiştiriciliğindeki artıştan ve tek yıllık baklagil artışından kaynaklandığı görülmektedir. Yörede tek yıllık baklagiller özellikle Macar fiği kışlık olarak ekilmekte ve ilkbahar sonunda hasat edilerek yerine silajlık mısır ekilmektedir. İstatistiklere girmemekle birlikte kışlık yem bezelyesini takiben silajlık mısır ekiminde ilde belirgin bir yayılış gözlenmektedir. Bu durum kışlık yem bezelyesinin Eskişehir için önemli bir alternatif olabileceğini göstermektedir. $\mathrm{Bu}$ da birim alandan elde edilen geliri artırarak ürünü ekonomik açıdan rekabet edebilir hale getirmektedir.

Desteklemelerde ülke tarımının modernizasyonu da gözetilerek desteklenecek minimum alan miktarı belirlenmelidir. Yem bitkileri desteklerinin, hayvansal üretimde de modernizasyonu sağlayacak destekler ile koordinasyon içinde yürütülmesi beklenen başarıyı artıracaktır. $\mathrm{Bu}$ sonuçlar ülke ölçeğinde yorumlanacak olursa; havzalara ve hatta aynı havzada yörelere göre öncelikli ve alternatif bitkiler ile destek miktarları belirlenmeli ve bunun hayvansal üretim destekleri ile uyumlu olarak yürütülmesi gerekmektedir. $\mathrm{Bu}$ süreçte diğer ürünler ile ilgili fiyat politikaları da yem bitkileri destekleri belirlenirken göz önünde bulundurulması gereken konulardır. Tek yönlü desteklerin, sürdürülebilirliğin sağlanması ve dolayısıyla ülke refahına katkısı olası değildir.

Ayrıca istatistikler incelendiğinde; yem bitkileri destekleri reel olarak artmadığı halde, yalnızca artış eğiliminde olsa bile bir sonraki üretim dönemi için çiftçi davranışının, yem bitkisi ekimini artırmak şeklinde oluştuğu görülmektedir. $\mathrm{Bu}$ da desteklemenin sürekliliğinin çiftçi davranış1 açısından önemini ortaya koymaktadır. Bu nedenle destek etkinliği araştırmalarına ve çiftçi davranışlarına yönelik sosyo-ekonomik çalışmalara ağırlık verilmesi gerekmektedir.

\section{KAYNAKLAR}

Açıkgöz, E., R. Hatipoğlu, S. Altınok, C Sancak, A. Tan ve D. Uraz., 2005. Yem Bitkileri Üretimi ve Sorunları. Türkiye Ziraat Mühendisliği VI. Teknik Kongresi Bildiriler: 3-7 Ocak 2005, Ankara. 503- 518.

Aksu N., Dellal İ., 2016. Afyonkarahisar İlinde Yem Bitkileri Desteğinin Büyükbaş Hayvancılık Faaliyetleri ile İlişkisinin Değerlendirmesi. Yüzüncü Y1l Üniversitesi Tarım Bilimleri Dergisi 26 (1): 52-60.

Alçiçek A., 2002. Süt Sığırı Rasyonu Yapımında Temel İlkeler. Ege Tarımsal Araştırma Enstitüsü Müdürlüğü Yayınları. No: 106., Menemen, İzmir.

Alçiçek, A., Kılıç, A., Ayhan, V., Özdoğan, M., 2010. Türkiye’de kaba yem üretimi ve sorunları. Türkiye Ziraat Mühendisliği 7. Teknik Kong., 11-15 Ocak, Ankara.

Altın, M. A. Gökkuş ve A. Koç, 2011. Çayır ve Mera Yönetimi Cilt I. T.C. Tarım ve Köyişleri Bakanlığı Yay., Ankara, $376 \mathrm{~s}$.

Avcıoğlu, R., Açıkgöz, E., Soya, H., Tan, M., 2000. Yem Bitkileri Üretimi. Türkiye Ziraat Mühendisliği V. Teknik Kongresi. 17-21 Ocak. Ankara, 567-584.

Cevher, C.,Karakurt, E., 2010. Mera Islah Çalışması Yürütülen Köylerde Yem Bitkisi Üretimini Arttırmaya Yönelik Yayım Çalışmasının Değerlendirilmesi. Merkez Araştırma Enstitüsü Dergisi. 19: (1-2).

Cevher, C., 2012. Islah Edilmiş Mera Alanlarının Sürdürülebilir Kullanımına Etki Eden Sosyo-Ekonomik Faktörler Üzerine Bir Araştırma. Basılmamış Doktora Tezi, Ankara.

Çelik, A., Demirbağ N., 2013. Türkiye'de Tarımsal Desteklemelerin Yem Bitkileri Ekiliş ve Üretim Üzerine Etkileri, Tarımsal Ekonomi ve Politika Geliştirme Enstitüsü Yayın No:215, Ankara.

Demir, N., Yavuz, F., 2010. An Analysis on Factors Effective in Benefiting from Forage Crops Support. Scientific Research and Essays, 5 (15): 2022-2026.

Dinler, Z., 2000. Tarım Ekonomisi. Ekin Yayınları 5. Basım, Bursa.

GTHB, 2016a. Gıda Tarım ve Hayvancılık Bakanlığı, Eskişehir İl Müdürlüğü, $\quad$ Faaliyet $\quad$ Raporu, 2015. (http://eskisehir.tarim.gov.tr/Belgeler/2015_Faaliyet_Rapor u (Erişim tarihi: 21.07.2016).

GTHB, 2016b. Gıda Tarım ve Hayvancılık Bakanlığı, Eskişehir İl Müdürlüğü, http://eskisehir.tarim.gov.tr/Menu/33/Eskisehir (Erişim tarihi: 26.07. 2016)

GTHB, 2016c. Gıda Tarım ve Hayvancılık Bakanlığı, Eskişehir İl Müdürlüğü Kayıtları, Eskişehir 2016.

Koc, A., A. Kaya, M.K. Gullap, H.I. Erkovan, M. Macit and M. Karaoglu, 2014. The effect of supplemental concentrate feed on live weight gain of yearling heifers over grazing season in subirrigate drange lands of East Anatolia. Turk J Vet Anim Sci., 38: 278-284.

Lardy, G,, 2016. Feeding Sugar Beet Byproducts to Cattle https://www.ag.ndsu.edu/publications/livestock/feedingsugar-beet-byproducts -to-cattle/as1365.pdf, 13.12.2016

Özkan, U., Demirbağ, N.Ş., 2016. Türkiyede Kaliteli Kaba Yem Kaynaklarını Mevcut Durumu. Türk Bilimsel Derlemeler Dergisi 9(1): 23-27.

Rehber E., 2013. Tarım Ekonomisi. Ekin Yayınları, Bursa. ISBN:978-605-5187-44-6

Sancar, C., Demir, O., Aksakal, V., Aksoy, A., 2016. Determining the Factors Affecting Farmers' Decision on Organic Livestock. Turkish Journal of Agriculture - Food Science and Technology. 4 (4): 313-317.

Sabanc1, O., Baytekin, H., Balabanlı, C., Acar, Z., 2010. Yem Bitkileri Üretiminin Artırılması Olanakları. http://www.zmo.org.tr/resimler/ekler/ 7e77c835af3d2a8_ek.pdf.( Erişim tarihi: 02.11.2016)

Shaver, R.,P. Hoffman, 2010. Use of Straw in Dairy Cattle Diets. http://fyi.uwex.edu/forage/files/2014/01/DairyStrawFOF.pdf, 13.12.2016. 
Eskişehir İlinde Yem Bitkileri Ekiliş Alanı ve Üretim Miktarı Üzerine Tarımsal Desteklemelerin Etkisi

Temel, S., Şahin, K., 2011. Iğdır İlinde Yem Bitkilerinin Mevcut Durumu, Sorunları ve Çözüm Önerileri. Yüzüncü Yı1 Üniv. Tarım Bilimleri Derg. 21(1): 64-72.

TKB, 2001.Tarım ve Köyişleri Bakanlı̆̆ 4342 Sayılı Mera Yönetmeliği, Ankara. T.C. Resmi Gazete 25 Nisan 2001 Sayı: 24383, Sayfa 40.

Turan, N., Özyazıcı, M.A., Tantekin, G.Y., 2015. Siirt İlinde Çayır Mera Alanlarından ve Yem Bitkilerinden Elde Edilen Kaba Yem Üretim Potansiyeli. Türkiye Tarımsal Araştırmalar Dergisi - 2(1): 69-75.

TÜIK, 2001. Türkiye İstatistik Kurumu, Bitkisel Üretim İstatistikleri https: // biruni. tuik. gov. tr/ bitkisel app/ bitkisel. zul/ (Erişim tarihi: 25 Temmuz 2016).
TÜIK, 2016a. Türkiye İstatistik Kurumu, Bitkisel Üretim İstatistikleri. https: // biruni. tuik. gov. tr/ bitkisel app/ bitkisel. zul/ (Erişim tarihi: 25 Temmuz 2016).

TÜIK, 2016b. Türkiye İstatistik Kurumu, Hayvansal Üretim İstatistikleri http://rapory.tuik.gov.tr (Erişim tarihi: 24 Temmuz 2016).

Yavuz, G., Ceylan, C., 2004. Polatlı İlçesinde Üreticilerin Yem Bitkileri Üretimine Karar Verme Sürecinde Etkili Faktörlerin Belirlenmesi Üzerine Bir Araştırma. Tarım Bilimleri Dergisi. 11 (2): 133-138.

Yolcu, H., Tan, M., 2008. Ülkemiz Yem Bitkileri Tarımına Genel Bir Bakış, Tarım Bilimleri Dergisi 14 (3): 303-312, Ankara Üniversitesi Ziraat Fakültesi. 